\title{
Evaluation of the antiproliferative potential of Cocos nucifera juice
}

\author{
Enegide Chinedu ${ }^{*}$, Ifeoma Agatha Onah², Paul Okesinachi Amaje ${ }^{3}$, Dabum Luka Jacob ${ }^{4}$ \\ ${ }^{1}$ Department of Pharmacology \& Toxicology, Faculty of Pharmaceutical Sciences, University of Nigeria, Nsukka, Nigeria \\ ${ }^{2}$ Department of Pharmaceutical Microbiology \& Biotechnology, Faculty of Pharmaceutical Sciences, University of Nigeria, Nsukka, Nigeria \\ ${ }^{3}$ Department of Microbiology, Faculty of Biological Sciences, University of Nigeria, Nsukka, Nigeria \\ ${ }^{4}$ Department of Human Physiology, Faculty of Medical Sciences, University of Jos, Jos, Nigeria
}

\section{A R T I C L E I N F O}

Article Type:

Short Communication

\section{Article History:}

Received: 22 December 2017

Accepted: 27 May 2018

\section{Keywords:}

Cocos nucifera

Coconut water

Antiproliferative potential

\begin{abstract}
A B S T R A C T
Introduction: The World Health Organization has predicted that the death caused by cancer may rise to a high rate of about 11.5 million in the year 2030. Cocos nucifera juice (Coconut water) is a known refreshing and nutritious beverage which is widely consumed traditionally for its nutritious and medicinal properties. Though assumptions traditionally suggest that it may also have an anticancer property, it is important to scientifically evaluate this property. The aim of this study is to ascertain if $C$. nucifera juice has an antproliferative effect.

Methods: The study was carried-out on rapid proliferating seeds (Sorghum bicolor) and the mean radicle lengths $(\mathrm{mm})$ was taken after 48 and 72 hours.

Results: The control group had an unrestricted progressive proliferation throughout the study. Methotrexate elicited significant $(P<0.001)$ antiproliferative effect, with percentage inhibition of 73.9 and $87.6 \%$ after 48 and 72 hours. C. nucifera juice $20 \% \mathrm{v} / \mathrm{v}$ concentration gave significant $(P<0.01)$ inhibitory effect of $49.9 \%$ after 72 hours. C. nucifera juice $40 \% \mathrm{v} / \mathrm{v}$ gave a significant $(P<0.01)$ effect of $46 \%$ and a more significant $(P<0.001)$ effect of $49.7 \%$ after 48 and 72 hours. C. nucifera juice $60 \% \mathrm{v} / \mathrm{v}$ had high significant $(P<0.001)$ activity after 48 and 72 hours, giving inhibitory effect of $55.3 \%$ and $80 \%$, respectively. C. nucifera juice and methotrexate combination had a good synergic effect, eliciting significant $(P<0.001)$ inhibitory effect of $73.4 \%$ and $80 \%$ after 48 and 72 hours, respectively.

Conclusion: The experimental results have unveiled that $C$. nucifera juice has a potential for eliciting antiproliferative effect.
\end{abstract}

Implication for health policy/practice/research/medical education:

Cocus nucifera juice elicited a significant anti-proliferative activity, hence it may serve as a cost effective tool for cancer prevention. Please cite this paper as: Chinedu E, Onah IA, Amaje PO, Jacob DL. Evaluation of the antiproliferative potential of Cocos nucifera juice. J Herbmed Pharmacol. 2018;7(3):124-128. doi: 10.15171/jhp.2018.21.

\section{Introduction}

Studies in the field of epidemiology have unveiled that dietary patterns are significantly associated with the prevention of various chronic diseases such as diabetes, heart disease, Alzheimer's disease and even cancer. The consumption of various natural plant products has however been reported to be highly associated with the reduction of the risk of cancer occurrence (1-3). This has led to the encouragement of consumption of natural plant products as a low cost tool for prevention of such diseases including cancer. Cancer is a major health problem today, as it is one of the leading causes of mortality globally. The World Health Organization has predicted that death caused by cancer may rise to a high rate of about 11.5 million in the year 2030. This by far exceeds the rate of about 7.4 million recorded deaths caused by cancer in 2004 (4). Cancer occurs as a result of events that alters both the properties and functions of the affected cells. However, some of the hallmarks of cancer include uncontrollable and sustained proliferation, evasion of apoptosis, angiogenesis and metastasis (5). The process of the formation of cancerous cells is a complex one, but however when it starts cannot 
be reverted. The progress can only be slowed down or terminated. Therefore, it is now believed that the best treatment for cancer is prevention. Cocos nucifera juice (Coconut water) is a known refreshing and nutritious beverage which has been widely consumed traditionally for its nutritious and medicinal properties $(6,7)$. Various medicinal properties of $C$. nucifera juice have been documented (8). Literature has shown that C. nucifera juice possesses a potential for boosting the human body antioxidant system (9). Reports have also shown it to be a valuable substitute for oral rehydration and intravenous hydration of patients especially in remote places where they are not readily available (10). It may also offer protection against myocardial infarction and control of hypertension $(11,12)$. It's effectiveness in the treatment of urinary tract infections, mineral poisonings, kidney and urethral stones have been stated (13). It has also been reported to possess significant anti-carcinogenic, antithrombotic and anti-aging properties $(14,15)$. Though assumptions traditionally suggest that it may also have an anticancer property, it is however important to scientifically evaluate this property. The aim of this study is to ascertain if Cocos nucifera juice has an antiproliferative effect.

\section{Materials and Methods}

Materials

Methotrexate injection (Korea United Pharm. Inc) was purchased from a pharmacy outlet in Jos. Fresh Cocos nucifera (coconut) fruit was harvested from a local garden and supplied by a local agricultural personnel in Jos. Authentication was done at the Federal College of Forestry Jos by Mr. J. Azila of the herbarium unit.

\section{Extraction}

The C. nucifera fruit was de-husked and broken gently, while the liquid endosperm (Cocos nucifera juice, i.e coconut water) was collected into a sterile container in an aseptic manner.

\section{Experimental Plant (Sorghum bicolor)}

The experimental plant Sorghum bicolor (guinea corn) was purchased from Angwan-Rukuba market, Jos. A viability test was carried-out on the seeds. This was done by pouring them into a bowl of water and then observed for floating. The floating ones were discarded, while the submerged ones were dried and cleansed with alcohol for usage.

\section{Antiproliferative evaluation}

The bench top assay method described by Ayinde et al (16), and modified by Chinedu et al (17), was adopted for this study. A concentration of methotrexate $50 \mu \mathrm{g} / \mathrm{mL}$ was prepared, while different concentrations (20\%, $40 \%$ and $60 \% \mathrm{v} / \mathrm{v}$ ) of the $C$. nucifera juice were also prepared. Six sterile petri-dishes were layered with cotton-wool and filter paper (Whatman No. 1). Twenty seeds of $S$. bicolor were placed into each layered petri-dish. The seeds serving as control were treated with $10 \mathrm{~mL}$ of distilled water. The seeds in the methotrexate group were treated with $10 \mathrm{~mL}$ of $50 \mu \mathrm{g} / \mathrm{mL}$ methotrexate. The test seeds were treated with different concentrations of C. nucifera juice preparation. The first group was treated with $10 \mathrm{~mL}$ of $20 \% \mathrm{v} / \mathrm{v}$ concentration, the second group was treated with $10 \mathrm{~mL}$ of $40 \% \mathrm{v} / \mathrm{v}$ concentration, and another group was treated with $10 \mathrm{~mL}$ of $60 \% \mathrm{v} / \mathrm{v}$ concentration. The last group was treated with $5 \mathrm{ml}$ of $50 \mu \mathrm{g} / \mathrm{mL}$ methotrexate and $5 \mathrm{~mL}$ of $50 \% \mathrm{v} / \mathrm{v}$ C. nucifera juice. All seeds were incubated in a dark room and observed for radicle growth after 24 hours. The mean length $(\mathrm{mm})$ of the radicles emerging from the seeds in each group was taken after 48 and 72 hours, respectively. The percentage growth was calculated as [mean radicle length treated/mean radicle length control] $\times 100$. Percentage inhibition was calculated as $100-\%$ growth as well.

\section{Statistical analysis}

The data obtained were expressed as mean \pm standard error mean (SEM). Two-way analysis of variance (ANOVA) and Bonferroni post hoc test were used to test for significance. GraphPad Prism software (version 5.02) was used for the analysis.

\section{Results}

The results showed that the control group had an unrestricted progressive proliferation (growth) throughout the study (Table 1, Figures 1 and 2). The percentage growth was $100 \%$ throughout the study, and there was no growth inhibition. All the treated groups showed reduced radicle growth throughout the study (Table 1, Figure 1). Methotrexate had significant $(P<0.001)$ effect on radicle proliferation after 48 and 72 hours, with percentage inhibition of $73.9 \%$ and $87.6 \%$ (Table 1, Figures 1 and 2). C. nucifera juice $20 \% \mathrm{v} / \mathrm{v}$ had a significant $(P<0.01)$ effect after 72 hours, eliciting an inhibitory effect of $49.9 \%$ (Table 1, Figures 1 and 2). C. nucifera juice 40\% $\mathrm{v} / \mathrm{v}$ gave a significant $(P<0.01)$ effect of $46 \%$ and a more

Table 1. Mean radicle length of Sorghum bicolor seeds treated with Cocos nucifera juice

\begin{tabular}{lcc}
\hline \multirow{2}{*}{ Treatment } & \multicolumn{2}{c}{ Mean Radicle Length (mm) } \\
\cline { 2 - 3 } & $\mathbf{4 8 ~ h}$ & $\mathbf{7 2 ~ h}$ \\
\hline Control (water) & $18.80 \pm 1.79$ & $48.30 \pm 4.147$ \\
MTX $50 \mu \mathrm{g} / \mathrm{mL}$ & $4.90 \pm 0.25^{* * *}$ & $6.00 \pm 0.60^{* * *}$ \\
CnJ 20\% v/v & $15.50 \pm 1.55$ & $39.40 \pm 4.07^{* *}$ \\
CnJ 40\% v/v & $10.15 \pm 0.88^{* *}$ & $24.30 \pm 2.84^{* * *}$ \\
CnJ 60\% v/v & $8.40 \pm 0.81^{* * *}$ & $12.10 \pm 1.02^{* * *}$ \\
CnJ+MTX & $5.00 \pm 0.61 * * *$ & $7.75 \pm 1.463^{* * *}$ \\
\hline
\end{tabular}

MTX $=$ Methotrexate, $\mathrm{CnJ}=\operatorname{Cocos}$ nucifera juice.

** $P<0.01, * * * P<0.001$, compared to control group. 


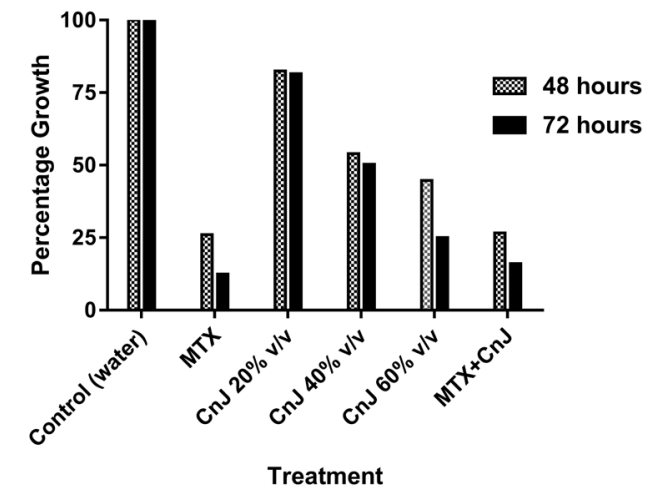

Figure 1. Percentage radicle growth of Sorghum bicolor seeds treated with of Cocos nucifera juice. MTX = Methotrexate, $\mathrm{CnJ}=$ Cocos nucifera juice.

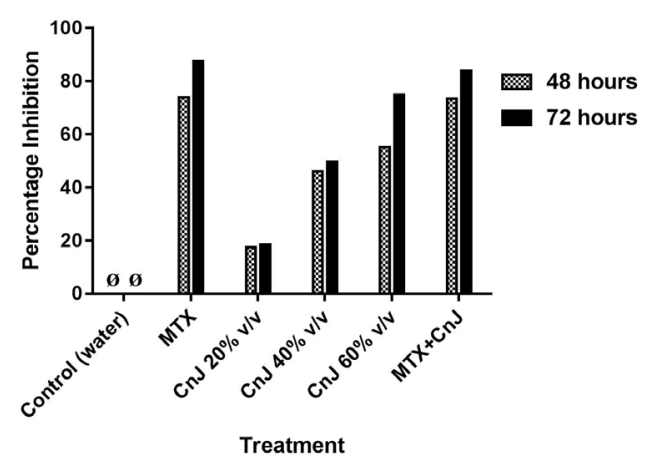

Figure 2. Antiproliferative (growth inhibitory) effect of Cocos nucifera juice on Sorghum bicolor seeds radicle. MTX = Methotrexate, $\mathrm{CnJ}=$ Cocos nucifera juice, $\varnothing=$ no antiproliferative activity

significant $(P<0.001)$ effect of $49.7 \%$ after 48 and 72 hours, respectively (Table 1, Figures 1 and 2). C. nucifera juice $60 \% \mathrm{v} / \mathrm{v}$ had high significant $(P<0.001)$ activity after 48 and 72 hours, giving inhibitory effect of $55.3 \%$ and $80 \%$, respectively (Table 1, Figures 1 and 2). The combination C. nucifera juice and methotrexate had a good synergic effect, eliciting significant $(P<0.001)$ inhibitory effect of $73.4 \%$ and $80 \%$ after 48 and 72 hours, respectively (Table 1, Figures 1 and 2).

\section{Discussion}

The search for a better method to curtail the menace of cancer has been a top priority to researchers globally. This is due to the fact that various methods and therapies currently available though have produced some levels of success, have not been able to arrest the condition effectively. As most of them have their short comings like being very expensive, not easily accessible and also having very serious adverse effects. Plant products have now risen to be the main source of drug discovery, as statistics have unveiled that about 3.5-4 million people globally, rely on plant sources for drug (18). History has also unveiled that more than $60 \%$ of the currently used anticancer drugs are from natural sources (including plant sources) (19). Since one of the prominent characteristics of cancer is rapid and uncontrollable proliferation, the effect of suspected anticancer agents on proliferation has been used as a criterion for determining their anticancer potential. The use of rapidly proliferating seeds radicle as a parameter for screening of suspected antiproliferative agents have been demonstrated previously by Shogbaike et al (20), Ayinde et al (21), McLauhlin et al (22), David et al (23), and Chinedu et al (24). Cancerous cells are known to show rapid proliferation and this also occurs with meristematic cells of seeds (including S. bicolor) under favourable conditions. This explains why this method was adopted for this study.

The results obtained from the study showed that there was a high unhindered growth of the control seeds radicle throughout the study. This reveals that the seeds of $S$. bicolor under favourable conditions proliferate rapidly. The seeds treated with methotrexate had significant $(P<0.001)$ decrease in mean radicle growth after 48 and 72 hours compared with control group. This result validates the use of methotrexate as a potent antiproliferative agent. It also reveals that it is capable of inhibiting rapidly proliferating cells of S. bicolor just like it does to cancer cells. The inhibitory effect produced was highest after 72 hours, with percentage inhibition of $87.59 \%$. C. nucifera juice $20 \% \mathrm{v} / \mathrm{v}$ showed a significant $(P<0.01)$ antiproliferative effect after 72 hours, with percentage inhibition of $18.43 \%$. C. nucifera juice $40 \% \mathrm{v} / \mathrm{v}$ as well gave a significant $(P<0.01)$ antiproliferative effect after 48 hours and even had a higher significant $(P<0.001)$ effect after 72 hours, with inhibitory rate of $46.01 \%$ and $49.69 \%$, respectively. C. nucifera juice $60 \% \mathrm{v} / \mathrm{v}$ had a highly significant $(P<0.01)$ antiproliferative effect after 48 hours and even a better significant $(P<0.001)$ effect after 72 hours. The percentage inhibition was $55.32 \%$ and $74.95 \%$ after 48 and 72 hours, respectively. The result showed that C. nucifera juice significantly inhibited the proliferation of $S$. bicolor radicle. However, this effect was in a dose dependent order, as higher doses gave a better effect. The effect was also time dependent, as better effects were observed with increase in time (i.e., the effect at 72 hours was better than that at 48 hours). The results from the study therefore give an indication that C. nucifera juice, in addition to its numerous medicinal effects already documented (8) may also possess a significant antiproliferative property. The various medicinal effects of $C$. nucifera juice have been attributed its chemical components. Several reports have unveiled the presence of vitamins, fatty acids, amino acids, organic acids, phytohormones, riboflavin, niacin, and vitamin $C$ in C. nucifera juice (25-31). Vitamin C, niacin and riboflavin are known antioxidants whose antioxidant properties have been previously documented $(24,32)$. Antioxidants are known to elicit antiproliferative activity and hence are potent anticancer agents (33). The antioxidant property of $C$. nucifera juice has been documented previously by Santos et al (30). Hence, the 
antiproliferative activity demonstrated by $C$. nucifera juice in this study may be attributed to the antioxidants (vitamin $\mathrm{C}$, niacin and riboflavin) present in it. The experimental result also showed a very good synergic effect between $C$. nucifera juice and methotrexate, producing a very high significant $(P<0.001)$ antiproliferative activity after 48 and 72 hours, with percentage inhibition of $73.40 \%$ and $83.95 \%$, respectively. This is also an indication that $C$. nucifera juice may serve as a good combination agent with methotrexate.

\section{Conclusion}

The experimental results have unveiled that C. nucifera juice has a potential for eliciting antiproliferive effect. This suggests that $C$. nucifera juice may possess potent anticancer activity and may be effective in cancer prevention.

\section{Authors' contributions}

All authors contributed significantly towards the success of the work.

\section{Conflict of interests}

None.

\section{Ethical considerations}

Ethical issues including plagiarism, misconduct, data fabrication, falsification, double publication or submission, redundancy, have been carefully observed by authors.

\section{Funding/Support}

None.

\section{References}

1. Temple NJ. Antioxidants and disease: More questions than answers. Nutr Res. 2000;20(3):449-59. doi: 10.1016/S02715317(00)00138-X.

2. Willett WC. Balancing life-style and genomics research for disease prevention. Science. 2002;296(5568):695-8. doi: 10.1126/science. 1071055 .

3. Doll R. An overview of the epidemiological evidence linking diet and cancer. Proc Nutr Soc. 1990;49(2):119-31.

4. NMH Fact sheet 2010. World Health Organization website. http://www.who.int/cancer/en/.

5. Hanahan D, Weinberg RA. The hallmarks of cancer. Cell. 2000;100(1):57-70.

6. George EF, Sherrington PD. Plant Propagation by Tissue Culture: Handbook and Directory of Commercial Laboratories. Edington, UK: Exegetics Ltd; 1984.

7. Janick J, Paull RE. The Encyclopedia of Fruit \& Nuts. Wallingford, UK: CAB International; 2008.

8. Yong JW, Ge L, Ng YF, Tan SN. The chemical composition and biological properties of coconut (Cocos nucifera L.) water. Molecules. 2009;14(12):5144-64. doi: 10.3390/ molecules14125144.

9. Evans P, Halliwell B. Micronutrients: oxidant/antioxidant status. Br J Nutr. 2001;85 Suppl 2:S67-74.
10. Campbell-Falck D, Thomas T, Falck TM, Tutuo N, Clem K. The intravenous use of coconut water. Am J Emerg Med. 2000;18(1):108-11.

11. Anurag P, Rajamohan T. Cardioprotective effect of tender coconut water in experimental myocardial infarction. Plant Foods Hum Nutr. 2003;58(3):1-12. doi: 10.1023/b:qu al.0000040363.64356.05.

12. Alleyne T, Roache S, Thomas C, Shirley A. The control of hypertension by use of coconut water and mauby: two tropical food drinks. West Indian Med J. 2005;54(1):3-8.

13. Macalalag EV Jr, Macalalag AL. Bukolysis: young coconut water renoclysis for urinary stone dissolution. Int Surg. 1987;72(4):247.

14. Rattan SI, Clark BF. Kinetin delays the onset of ageing characteristics in human fibroblasts. Biochem Biophys Res Commun. 1994;201(2):665-72.

15. Vermeulen K, Strnad M, Krystof V, Havlicek L, Van der Aa A, Lenjou M, et al. Antiproliferative effect of plant cytokinin analogues with an inhibitory activity on cyclindependent kinases. Leukemia. 2002;16(3):299-305. doi: 10.1038/sj.leu.2402378.

16. Ayinde BA, Omogbai EKI, Ikpefan EO. Comparative cytotoxic and antiproliferative effects of Persea americana mill (Lauraceae) leaf, stem and root barks. Niger J Pharm Sci. 2011;10:16-26.

17. Chinedu E, Arome D, Ameh SF, Ameh GE. Evaluation of the anti-proliferative and cytostatic effect of Citrus sinensis (orange) fruit juice. Int J Appl Basic Med Res. 2014;4(Suppl 1):S20-2. doi: 10.4103/2229-516x.140711.

18. Farnsworth NR. Screening for new medicines. In: Wislson EO, ed. Biodiversity. Washington DC: National Academy Press; 1988:83-97.

19. Tan G, Gyllenhaal C, Soejarto DD. Biodiversity as a source of anticancer drugs. Curr Drug Targets. 2006;7(3):265-77.

20. Sogbaike DA, Ogundaini AO, Adesanya SA. The effects of some synthesized stilbene analogues on Artemia salina naupalii and germination of Sorghum bicolor seeds. Niger J Nat Prod Med. 2002;6:19-25. doi: 10.4314/njnpm. v6i1.11686.

21. Ayinde BA, Agbakwuru U. Cytotoxic and growth inhibitory effects of the methanol extract Struchium sparganophora Ktze (Asteraceae) leaves. Pharmacogn Mag. 2010;6(24):2937. doi: 10.4103/0973-1296.71795.

22. McLaughlin JL, Chang C, Smith DI. Bench-top bioassays for the discovery of bioactive natural products: An update. In: Atta-ur-Rahman, eds. Studies in Natural Products Chemistry. Vol 9. Amsterdam: Elsevier Science Publishers; 1991:383-409.

23. Arome D, Chinedu E, Fidelis Ameh S, Agbafor A, Mbonne Esenju R. Evaluation of anti-proliferative activities of aqueous leaf and root extracts of Cymbopogon citratus. J Pharm Biol Sci. 2013;1(5):56-60.

24. Chinedu E, Arome D, Jacob DL. Preliminary assessment of the antiproliferative potential of Ananas comosus (pineapple) fruit juice. J HerbMed Pharmacol. 2016;5(2):50-3.

25. Santoso U, Kubo K, Ota T, Tadokoro T, Maekawa A. Nutrient composition of kopyor coconuts (Cocos nucifera L.). Food Chem. 1996;57(2):299-304. doi: 10.1016/03088146(95)00237-5.

26. Ma Z, Ge L, Lee AS, Yong JW, Tan SN, Ong ES. Simultaneous 
analysis of different classes of phytohormones in coconut (Cocos nucifera L.) water using high-performance liquid chromatography and liquid chromatography-tandem mass spectrometry after solid-phase extraction. Anal Chim Acta. 2008;610(2):274-81. doi: 10.1016/j.aca.2008.01.045.

27. Wu Y, Hu B. Simultaneous determination of several phytohormones in natural coconut juice by hollow fiber-based liquid-liquid-liquid microextraction-high performance liquid chromatography. J Chromatogr A. 2009;1216(45):7657-63. doi: 10.1016/j.chroma.2009.09.008.

28. Kobayashi H, Morisaki N, Tago Y, Hashimoto Y, Iwasaki S, Kawachi E, et al. Structural identification of a major cytokinin in coconut milk as 14-O-(3-O-[beta-Dgalactopyranosyl-(1-->2)-alpha-D-galactopyranosyl(1-->3)-alpha-L-arabinofuranosyl]-4-O-(alpha-Larabinofuranosyl)- beta-d-galactopyranosyl)-trans-zeatin riboside. Chem Pharm Bull (Tokyo). 1997;45(2):260-4.

29. Yong JW, Ge L, Ng YF, Tan SN. The chemical composition and biological properties of coconut (Cocos nucifera L.) water. Molecules. 2009;14(12):5144-64. doi: 10.3390/ molecules 14125144.

30. Santos JL, Bispo VS, Filho AB, Pinto IF, Dantas LS, Vasconcelos DF, et al. Evaluation of chemical constituents and antioxidant activity of coconut water (Cocus nucifera L.) and caffeic acid in cell culture. An Acad Bras Cienc. 2013;85(4):1235-47. doi: 10.1590/0001-37652013105312.

31. Sego S. Niacin: An antioxidant and nutrition supplement. http://www.clinicaladvisor.com/alternative-meds-update/ niacin-an-antioxidant-and-nutrition-supplement/ article/244396/. Accessed May 2018.

32. Amini-Sarteshnizi N, Mobini-Dehkordi M, KhosraviFarsani S, Teimori H. Anticancer activity of ethanolic extract of propolis on AGS cell line. J HerbMed Pharmacol. 2015;4(1):29-34.

33. Sajjadi SE, Ghanadian M, Haghighi M, Mouhebat L. Cytotoxic effect of Cousinia verbascifolia Bunge against OVCAR-3 and HT-29 cancer cells. J HerbMed Pharmacol. 2015;4(1):15-9. 